\title{
High Absorption Reticulocyte Measurement
}

National Cancer Institute

\section{Source}

National Cancer Institute. High Absorption Reticulocyte Measurement. NCI Thesaurus. Code C116188.

The determination of the amount of high absorption reticulocytes present in a sample. 